Check for updates

Cite this: RSC Adv., 2018, 8, 19610

\title{
Low-temperature, simple and efficient preparation of perovskite solar cells using Lewis bases urea and thiourea as additives: stimulating large grain growth and providing a PCE up to $18.8 \% \dagger$
}

\author{
Cheng-Ming Hsieh, ${ }^{a}$ Yung-Sheng Liao, ${ }^{b}$ Yan-Ru Lin, ${ }^{b}$ Chih-Ping Chen, (DD *b \\ Cheng-Min Tsai, (D) ${ }^{a}$ Eric Wei-Guang Diau ${ }^{a}$ and Shih-Ching Chuang (D) *a
}

Received 13th April 2018

Accepted 20th May 2018

DOI: $10.1039 / c 8 \mathrm{ra03175d}$

We demonstrated that two Lewis bases - urea and thiourea - acted as efficient additives for $\mathrm{CH}_{3} \mathrm{NH}_{3}(\mathrm{MA})$ $\mathrm{Pbl}_{3-x} \mathrm{Cl}_{x}$ and $\mathrm{MAPbl}_{3}$ perovskite solar cells (PSCs) and observed a significant increase in PCE for the MAPbl 3 devices in the presence of $1 \%$ urea with a remarkable PCE of $18.8 \%$ using an extremely low annealing temperature $\left(85^{\circ} \mathrm{C}\right)$.

rsc.li/rsc-advances

structures led to formation of the under-coordinated lead ion

\section{Introduction}

Perovskite solar cells (PSCs) have become one of the most promising candidate technologies in next generation photovoltaics because of their high performance, solution processing techniques and potentially low cost. ${ }^{1-6}$ The quality of perovskites can be improved by solvent annealing, thermal treatment, ${ }^{7,8}$ or using additives ${ }^{9-11}$ to alter the morphology of the perovskites. In recent reports, the PCEs can reach a maximum of $22.7 \% .^{5,6}$ Theoretically speaking, it may produce a PCE of more than $30 \%$ with an improvement in fill factor (FF) and open circuit voltage $\left(V_{\mathrm{oc}}\right) \cdot{ }^{\mathbf{1 2 - 1 4}}$ The incorporation of additive has been recognized as an efficient methodology to increase the performance of PSCs. ${ }^{15-18}$ Previous reports have demonstrated that incorporating diiodooctane (DIO), $\mathrm{NH}_{4} \mathrm{Cl}^{\mathbf{1 9 , 2 0}}$ and alkylammonium iodides ${ }^{\mathbf{1 1 2 2}}$ can increase the performance of PSC devices. Furthermore, the inserting of bulky cations can induce formation of $2 \mathrm{D}$ perovskites, which has been shown to improve the stability of PSCs. ${ }^{22}$ Recently, studies on additives further suggested the passivation of grain boundaries of perovskites for PCE enhancement; ${ }^{23-26}$ for instances, doping perovskites with pyridine, ${ }^{27}$ tri $\left(n\right.$-octyl)phosphine oxide,$^{28}$ polymers ${ }^{9}$ and fullerenes. $^{29,30}$ The use of these additives with particular functional groups led to an expansion of the perovskite grains and significantly reduced the recombination of charges at the grain boundaries of the perovskites. ${ }^{31}$ Typically, these grain boundaries ended with functionalities of either halogens or alkylammonium ions. Because thermal instability of these

${ }^{a}$ Department of Applied Chemistry, National Chiao Tung University, Hsinchu, Taiwan. E-mail: jscchuang@faculty.nctu.edu.tw

${ }^{b}$ Department of Materials Engineering, Ming Chi University of Technology, New Taipei City, Taiwan.E-mail: cpchen@mail.mcut.edu.tw

$\dagger$ Electronic supplementary information (ESI) available: Device fabrication condition and experimental detail. See DOI: 10.1039/c8ra03175d
$\left(\mathrm{Pb}^{2+}\right)$ and $\mathrm{Pb}-\mathrm{I}$ antisite defects at grain boundaries, such a notion increased the number of trap states leading to charge accumulation and carrier recombination. ${ }^{32}$ Yang and coworkers first used urea and thiourea as additives for $\mathrm{CH}_{3}$ $\mathrm{NH}_{3}$ (MA) $\mathrm{PbI}_{3}$ derived normal (ITO/TiO ${ }_{2}$ ) PSCs, and demonstrated a PCE of $18.25 \%$ using an annealing temperature of $100{ }^{\circ} \mathrm{C}^{10}$ Meng et al. used DMSO/urea to increase the PCE of normal devices up to $20.06 \%$ with the perovskites $\left(\mathrm{FAPbI}_{3}\right)_{0.75}\left(\mathrm{MAPbI}_{3}\right)_{0.17}\left(\mathrm{MAPbBr}_{3}\right)_{0.08}$ and urea derived antisolvent washing process. ${ }^{33}$ Considering the complexity of perovskite compositions and the myriad fabricating parameters involved in the previous process, we explored the urea and thiourea as simple precursor additives for inverted $\left(\mathrm{MAPbI}_{3-x^{-}}\right.$ $\mathrm{Cl}_{x}$ and $\mathrm{MAPbI}_{3}$ ) PSCs. We adopted the ITO/NiO ${ }_{x}$ or PEDOT:PSS/ perovskite/PCBM/Ag structure and found the performance up to $18.8 \%$ with little hysteresis for urea-derived devices using a low annealing temperature, as low as $85^{\circ} \mathrm{C}$. In particular, the grain size of perovskite can be grown up to $935 \mathrm{~nm}$-which was as twice large as those using conventional method and became a key factor on contributing to the high PCE.

\section{Results and discussion}

We studied the effects for perovskites in the presence of urea and thiourea (Fig. 1a), and analyzed these perovskites thin films (w/ or w/o additives) using ultraviolet-visible spectroscopy (UVvis), scanning electron microscopy (SEM) and grazing incidence wide angle X-ray diffraction (GIWAXS) measurements and varied the fabricated conditions-annealing temperatures and film compositions. These Lewis bases induced the intermolecular forces and were proven to be the passivation for trap states and led to efficient inter-grain carriers transporting. ${ }^{27,32}$ First, we fabricated the PSCs using the structure of ITO/ 

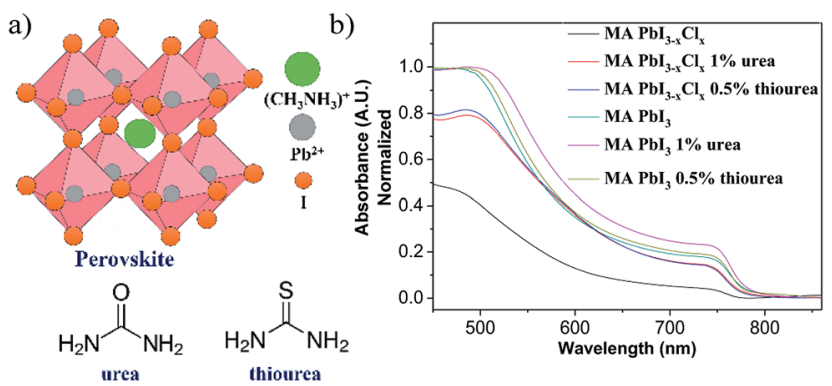

Fig. 1 (a) Chemical structure of perovskite, urea and thiourea (b) UVvis absorption spectra of perovskites with and without additives.

PEDOT:PSS/MAPbI ${ }_{3-x} \mathrm{Cl}_{x} / \mathrm{PCBM} / \mathrm{Ag}$. We manipulated the concentration of urea and thiourea to the $\mathrm{MAPbI}_{3-x} \mathrm{Cl}_{x}$ system at $0.5 \%, 1 \%$, and $3 \%$ as additives to $30 \mathrm{wt} \%$ of $\mathrm{MAPbI}_{3-x} \mathrm{Cl}_{x}$ precursor. We observed that the layers of $\mathrm{MAPbI}_{3-x} \mathrm{Cl}_{x}$ could turn into a dark brown perovskite within 10 seconds from yellow colored precursors upon annealing at $90{ }^{\circ} \mathrm{C}$ with the addition of $0.5 \%, 1 \%$ and $3 \%$ of urea and thiourea, respectively. For normal films, the precursor didn't change from yellow to dark brown at $90{ }^{\circ} \mathrm{C}$ in 60 minutes until an extended annealing for $2.5 \mathrm{~h}^{34}$ The urea- and thiourea-derived films changed to opaque appearance in 30 minutes, which indicated an overcrystallization of the perovskites. ${ }^{34}$ Therefore, we reduced the temperature to 80,75 and $65{ }^{\circ} \mathrm{C}$ and fixed the additive concentration with $0.5 \%$ and $1 \%$. We observed that the surface of the perovskite films still over-crystallized when $0.5 \%$ and $1 \%$ of urea was added at $80{ }^{\circ} \mathrm{C}$ and heated at $75{ }^{\circ} \mathrm{C}$ for 2.5 hours, respectively (Fig. S1 and S2 $\dagger$ ). The addition of $1 \%$ urea at $65{ }^{\circ} \mathrm{C}$ for $4.5 \mathrm{~h}$ resulted in as similar appearance of perovskites as a normal cell as shown in Fig. S1. $\dagger$ Compared with the normal $\mathrm{MAPbI}_{3-x} \mathrm{Cl}_{x}$, the film showed as yellow as colored precursor (Fig. S3) $\dagger$. Similar phenomena were observed for thioureaderived films (Fig. S2c to $\mathrm{c}-2 \dagger$ ). The addition of $0.5 \%$ thiourea at $70{ }^{\circ} \mathrm{C}$ for 2.5 hours allowed the optimized formation of perovskites. It was noteworthy that the transformation of $\mathrm{MAPbI}_{3-x} \mathrm{Cl}_{x}$ from precursor to under the annealing temperature below $75{ }^{\circ} \mathrm{C}$ for 2 hours was incomplete for the perovskite films (w/o thiourea) since we can clearly observe the yellow appearance throughout the process. Fig. 1b showed the UV-vis for $1 \%$ urea $\left(65{ }^{\circ} \mathrm{C}, 4.5 \mathrm{~h}\right)$ and $0.5 \%$ thiourea $\left(75^{\circ} \mathrm{C}, 2.5 \mathrm{~h}\right)$ derived films. Compared with normal films, we observed an increase in the intensity of the absorbance. This implied that the additives might improve the morphology (coverage) of $\mathrm{MAPbI}_{3-x} \mathrm{Cl}_{x} \cdot{ }^{35}$ Similar phenomena was observed for $\mathrm{MAPbI}_{3}$ films when compared with the normal films at same fabrication condition with annealing at $100{ }^{\circ} \mathrm{C}$ for $10 \mathrm{~min}$ on $\mathrm{NiO}_{x}$ surface (Fig. 1b).

For a standard $\mathrm{MAPbI}_{3-x} \mathrm{Cl}_{x}$, it required an annealing at $90{ }^{\circ} \mathrm{C}$ for 2.5 hours to provide a coverage rate of $94 \%$ (Fig. S4b $\dagger$ ). The surface morphology of the $\mathrm{MAPbI}_{3-x} \mathrm{Cl}_{x}$ (w/o additive at $65{ }^{\circ} \mathrm{C}$ for $4.5 \mathrm{~h}$ ) exhibited more holes and with a coverage of 82.7\% (Fig. S4a $\dagger$ ). The incomplete transformation led to small grain size and poor surface coverage. As our expected, the surface coverage $(97.7 \%)$ of the $1 \%$ urea-derived film (with a relatively lower annealing temperature of $65{ }^{\circ} \mathrm{C}$ for 4.5 hours) was greatly improved since the pores were reduced and the grain boundaries were relatively more continuous (Fig. S4c $\dagger$ ). Compared with the devices annealed at $90{ }^{\circ} \mathrm{C}$ w/o additives, the coverage increased from $94.0 \%$ to $97.7 \%$ (Fig. S4b and c $\dagger$ ). We found that the coverage of $0.5 \%$ thiourea derived perovskite showed a best coverage of $98.9 \%$ with the annealing temperature of $75{ }^{\circ} \mathrm{C}$ for 2.5 hours (Fig. S4d $\dagger$ ). As shown in Fig. $2 \mathrm{a}-\mathrm{c}$, it can be observed that $\mathrm{MAPbI}_{3}$-based perovskites showed a significant increase in crystal grain size compared to normal perovskite thin film after addition of $1 \%$ urea with $100{ }^{\circ} \mathrm{C}$ annealing for 10 minutes-the grain size increased from $184.9 \mathrm{~nm}$ to $368.9 \mathrm{~nm}$. Similarly, the grain size increased to $369.8 \mathrm{~nm}$ upon addition of $0.5 \%$ thiourea. We observed a significantly increase in grain size under $85{ }^{\circ} \mathrm{C}(10 \mathrm{~min})$ annealing process. The grain sizes of $1 \%$ urea and $0.5 \%$ thiourea derived films increased from $102.0 \mathrm{~nm}$ to 935.1 and $891.0 \mathrm{~nm}$, respectively (Fig. 2d-f). For 1\% urea derived perovskites at an annealing temperature of $65^{\circ} \mathrm{C}$ for $20 \mathrm{~min}$, the grain size increased from $93.2 \mathrm{~nm}$ to $608.9 \mathrm{~nm}$, and the grains by addition of $0.5 \%$ thiourea increased to $895.2 \mathrm{~nm}$ (Fig. S5a-c $\dagger$ ). Therefore, it was evidenced by SEM analysis that the addition of small amount of urea or thiourea can efficiently promote the growth of $\mathrm{MAPbI}_{3-x} \mathrm{Cl}_{x}$ thin films at a lower annealing temperature-resulting in a relatively flat film with less holes. In the $\mathrm{MAPbI}_{3}$, we observed the greatly increase in grain size of perovskites, implied electrons and holes can be more effectively transported to the corresponding charge transport layer, and lower leakage current was expected at the interfaces that enhanced the PCE.

According to GIWAXS analysis in Fig. S6, $\uparrow$ there were some (110) signatures but no significant (220) signatures when the $\mathrm{MAPbI}_{3-x} \mathrm{Cl}_{x}$ based precursor was annealed at $65{ }^{\circ} \mathrm{C}$ for 4.5 hours without the addition of additives. We speculated that the annealing temperature could be too low to fully convert the precursor solution into perovskite thin film. With the increase of annealing temperature, it showed obvious characteristic peaks at (110) and $(220)$ at $75^{\circ} \mathrm{C}$. It can be assumed that the precursor solution has been converted to a better perovskite thin film. However, upon addition of $1 \%$ urea with annealing at $65{ }^{\circ} \mathrm{C}$, the significant (110) and (220) signature signals were observed. Therefore, it can be inferred that the precursor

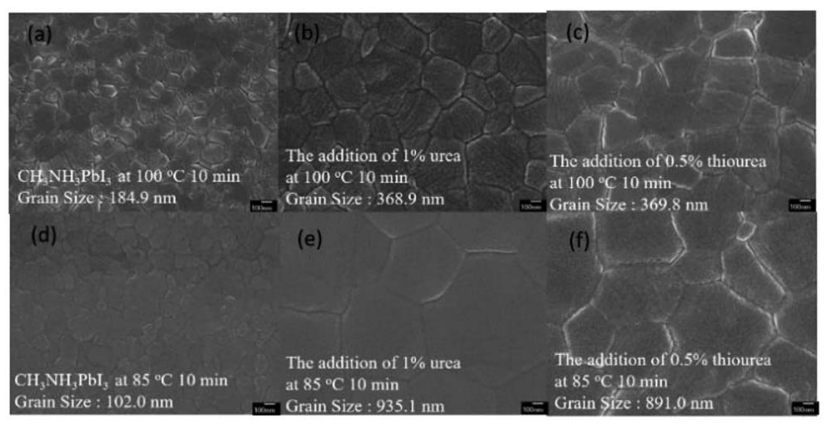

Fig. $2 \mathrm{FE}-\mathrm{SEM}$ images of $\mathrm{MAPb}_{3}$ perovskite thin films under different conditions (a) $\mathrm{MAPbl}_{3}$, (b) $1 \%$ urea, (c) $0.5 \%$ thiourea at $100{ }^{\circ} \mathrm{C}$ for $10 \mathrm{~min}$, respectively; (d) $\mathrm{MAPbl}_{3}$, (e) $1 \%$ urea, (f) $0.5 \%$ thiourea at $85^{\circ} \mathrm{C}$ for $10 \mathrm{~min}$, respectively, (scale bar $100 \mathrm{~nm}$ ). 
solution has been effectively converted into a perovskite thin film. However, after using $0.5 \%$ thiourea as an additive with annealing at $75{ }^{\circ} \mathrm{C}$ for 2.5 hours, intense (110) and (220) signature peaks of the perovskite thin film than the undoped perovskite were observed. It can be concluded that the precursor solution can be more effectively converted into a crystalline perovskite thin film using $0.5 \%$ thiourea as an additive. Therefore, it was proved that the annealing temperature can be reduced to help effectively conversion of the additives derived perovskite precursors into a well crystalline perovskite thin film by GIWAXS analysis. Furthermore, the intensity of the characteristic peaks, (110) and (220), changedwhich proved that doping urea and thiourea as additives can effectively affect the nucleation and growth of the grains. Similar phenomenon was observed for $\mathrm{MAPbI}_{3}$, the addition of urea and thiourea in $\mathrm{MAPbI}_{3}$-based perovskites at $100{ }^{\circ} \mathrm{C}$ for 10 minutes showed an obvious and stronger characteristic peaks of (110) and (220) when compared with the $\mathrm{MAPbI}_{3}$ without additive (Fig. 3a). In an annealing temperature at $85{ }^{\circ} \mathrm{C}$ for 10 minutes, $1 \%$ urea derived $\mathrm{MAPbI}_{3}$ film showed stronger (110) and (220) characteristic peak signals and no other extra peaks were generated. This implied that the addition of urea in the $\mathrm{MAPbI}_{3}$ system can effectively help the grain growth and improve the efficiency in a relatively low temperature environment without affecting the perovskite structure.

Table $\mathrm{S} 1 \dagger$ summarized the performance of $\mathrm{MAPbI}_{3-x} \mathrm{Cl}_{x}$ devices. The PCEs of normal devices $\left(90{ }^{\circ} \mathrm{C}\right)$ were $8.8 \pm 0.9 \%$. According to Table S1 and Fig. S7, $\dagger$ upon addition of $1 \%$ urea
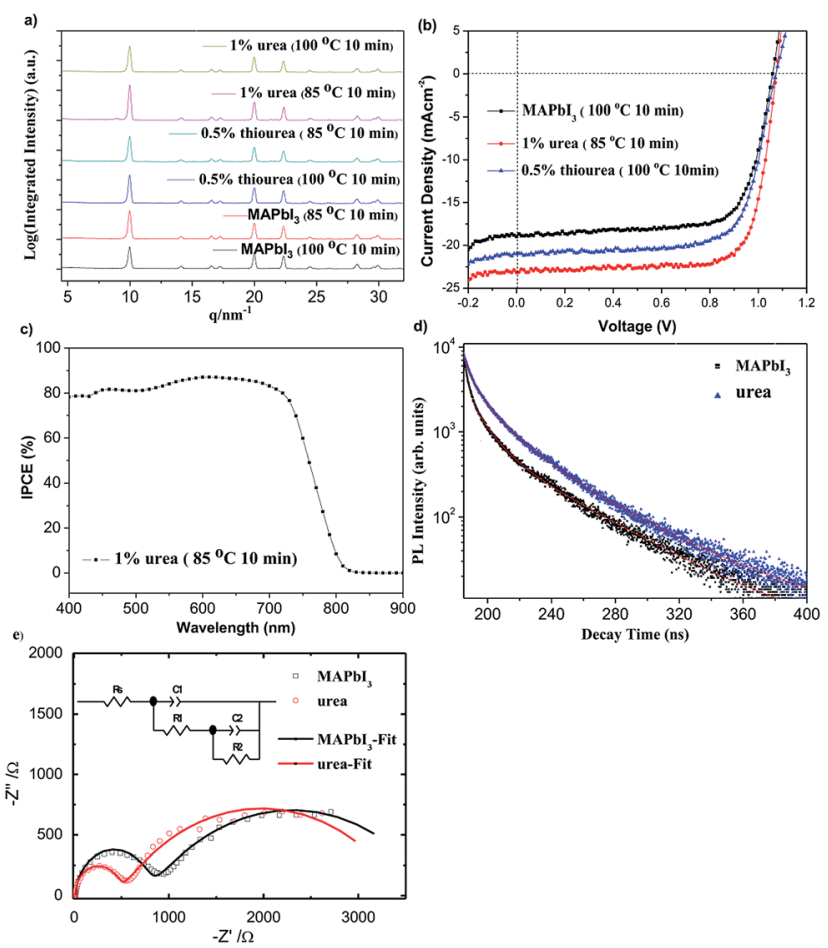

Fig. 3 (a) GIWAXS patterns, (b) J-V curves, (c) IPCE, (d) TRPL decay curves and (e) electrochemical impedance spectral (EIS) Nyquist plots (the symbols are experimental data, the solid curves are fitting data and the corresponding electronic circuit is shown on top inset) for $\mathrm{MAPbl}_{3}$ PSCs. and $0.5 \%$ thiourea to the perovskite devices, there were clear improvements on short circuit current density $\left(J_{\text {sc }}\right)$ and $V_{\text {oc }}$. We observed that the better perovskite thin films can be obtained at lower temperature upon addition of $1 \%$ urea or $0.5 \%$ thiourea as compared to the normal devices. The PCEs of the control devices at $65{ }^{\circ} \mathrm{C}$ was $4.1 \pm 1.0 \%$ while the PCEs of $1 \%$ urea derived devices at the annealing temperature of $65{ }^{\circ} \mathrm{C}$ was 13.0 $\pm 0.39 \%$. When compared with a normal cell, we observed an increase in PCEs of $34.7 \%$ from 9.8 to $13.2 \%$. It was reproducible for the devices with addition of urea at the annealing temperature of $65{ }^{\circ} \mathrm{C}$, so were the devices with doping $0.5 \%$ thiourea. Based on the $R_{\mathrm{sh}}$ values, we inferred that the $R_{\mathrm{sh}}$ values increased from 231.6 to $576.7 \Omega \mathrm{cm}^{2}$ upon doping with $1 \%$ urea. The resulted suggested that the perovskite precursor can be converted into a smooth $\mathrm{MAPbI}_{3-x} \mathrm{Cl}_{x}$ with high coverage led to efficient hole/electron transport, low leakage current and improved in $J_{\mathrm{sc}}$ values; therefore, the PCE of the PSC device was relatively increased. The device showed a slight increase in $J_{\mathrm{sc}}$ upon addition of $0.5 \%$ thiourea as an additive, presumably because of the good surface morphology of the perovskite thin film after annealing. Therefore, it caused reduction of energy levels and defects; a larger parallel resistance was resulted. As shown in Table 1 , the PCEs of normal MAPbI ${ }_{3}$-based devices prepared at $100{ }^{\circ} \mathrm{C}$ were $14.4 \pm 0.3 \%$. With the addition of $1 \%$ urea and $0.5 \%$ thiourea, the $J_{\mathrm{sc}}$ and FF values were significantly increased at different heating temperatures, so that the PCEs can be increased. The PCEs of the normal devices at $85{ }^{\circ} \mathrm{C}$ was $13.1 \pm 0.3 \%$ (Table $\mathrm{S} 2 \dagger$ ). The PCEs of the $1 \%$ urea derived devices $\left(85^{\circ} \mathrm{C}\right)$ was $18.5 \pm 0.3$ with a best performance of $18.8 \%$, along with a $J_{\mathrm{sc}}$ of $22.58 \mathrm{~mA} \mathrm{~cm}^{-2}$, the $V_{\mathrm{oc}}$ of $1.06 \mathrm{~V}$ and the $\mathrm{FF}$ of $78.5 \%$ (Table 1 and Fig. 3b). The devices from $85{ }^{\circ} \mathrm{C}$ outperformed than those derived from the $100{ }^{\circ} \mathrm{C}$ process due to the greater grain size (Fig. 2). At an annealed temperature of $65{ }^{\circ} \mathrm{C}(10 \mathrm{~min})$, the PCEs of the normal devices were $7.0 \pm 0.2 \%$ while the PCEs of the $1 \%$ urea derived devices were $15.9 \pm 0.3 \%$. This value is record high among the highest reported performance for PSC under such low annealing condition. We observed an increase in performance for the devices in the presence of $0.5 \%$ thiourea (at the annealing temperature of 100 ${ }^{\circ} \mathrm{C}$ ) with the PCEs $16.2 \pm 0.05 \%$ (Table S2 and Fig. S8†). Since hysteresis effect appeared to be widespread in PSCs, we found that the hysteresis effect of the device after addition of $1 \%$ urea $\left(85{ }^{\circ} \mathrm{C}, 10 \mathrm{~min}\right.$ ) was not significant, and the $J-V$ curves for the forward and reverse scans with various delay times were similar (Table S3†).

Based upon the incident photon-to-current efficiency (IPCE) graph in Fig. $\mathrm{S} 9, \uparrow$ the spectra of $\mathrm{MAPbI}_{3-x} \mathrm{Cl}_{x}$ PSCs were similar. The contribution of IPCE was about located at wavelengths of 400 and $800 \mathrm{~nm}$. At annealing temperature of $65{ }^{\circ} \mathrm{C}$ for 4.5 hours, the maximum of IPCE located at $600 \mathrm{~nm}$ increased from $17 \%$ to $77 \%$ after using $1 \%$ urea as additives. It was presumed that the perovskites with additives were effectively modified so that defects and trap levels were reduced. Therefore, it required less energy for grain growth and achieved a comparably high $J_{\mathrm{sc}}$ value at $65{ }^{\circ} \mathrm{C}$. It can be observed from Fig. S10 $\dagger$ that the main contribution of IPCE spectra was about $450 \mathrm{~nm}$ to $750 \mathrm{~nm}$ upon addition of $0.5 \%$ thiourea under the same annealing 
Table 1 Photovoltaic parameters of $\mathrm{MAPbl}_{3}$ based PSC devices prepared under various fabrication conditions and different annealing temperature

\begin{tabular}{llllll}
\hline Devices & Condition & $J_{\text {sc }}\left(\mathrm{mA} \mathrm{cm}^{-2}\right)$ & $V_{\text {oc }}(\mathrm{V})$ & FF $(\%)$ & PCE $(\%)$ \\
\hline Normal & $100^{\circ} \mathrm{C}(10 \mathrm{~min})$ & $19.0 \pm 0.4$ & $1.05 \pm 0.02$ & $73.8 \pm 2.2$ & $14.4 \pm 0.3$ \\
Urea & $85^{\circ} \mathrm{C}(10 \mathrm{~min})$ & $22.4 \pm 0.2$ & $1.06 \pm 0.01$ & $77.9 \pm 1.2$ & $18.5 \pm 0.3$ \\
Thiourea & $100^{\circ} \mathrm{C}(10 \mathrm{~min})$ & $21.0 \pm 0.0$ & $1.07 \pm 0.01$ & $72.2 \pm 0.1$ & $16.2 \pm 0.1$
\end{tabular}

${ }^{a}$ Best performance. ${ }^{b} R_{\mathrm{Sh}}=1417.1 \Omega \mathrm{cm}^{2}, R_{\mathrm{s}}=32.8 \Omega \mathrm{cm}^{2} .{ }^{c} R_{\mathrm{sh}}=3003.3 \Omega \mathrm{cm}^{2}, R_{\mathrm{s}}=31.3 \Omega \mathrm{cm}^{2} .{ }^{d} R_{\mathrm{sh}}=1030.2 \Omega \mathrm{cm}^{2}, R_{\mathrm{s}}=30.2 \Omega \mathrm{cm}^{2}$.

conditions, in which IPCE increased from $73.9 \%$ to $83.9 \%(640$ $\mathrm{nm})$. Because the increase in grain size and UV-vis absorbance, the $1 \%$ urea derived $\mathrm{MAPbI}_{3}$ devices showed the highest IPCE located at $610 \mathrm{~nm}$ with an intensity of $87.4 \%$ (Fig. $3 \mathrm{c}$ and S10†). To further investigate the effects on performance of $\mathrm{MAPbI}_{3}$ based perovskite thin films upon adding urea, we conducted a time-resolved photoluminescence (TRPL) measurements. Fig. 3d showed PL decay curves of $\mathrm{MAPbI}_{3}$-based perovskite thin films and the addition of $1 \%$ urea perovskite thin films. Table. $\mathrm{S} 4 \uparrow$ summarized the PL carrier lifetimes parameters. We found that lifetimes $\tau_{1}$ (ns) and $\tau_{2}$ (ns) were only $10.3 \mathrm{~ns}$ and $2.3 \mathrm{~ns}$, respectively, when $\mathrm{MAPbI}_{3}$-based perovskites were urea free. After urea was added, $\tau_{1}(\mathrm{~ns})$ and $\tau_{2}(\mathrm{~ns})$ increased to $16.1 \mathrm{~ns}$ and $4.3 \mathrm{~ns}$, respectively. This indicated that the addition of urea can prolong the carrier life-time and reduce the occurrence of trap defects and recombination. To characterize the internal resistance and charge transfer kinetics of PSCs w/ or w/o additive, electrochemical impedance spectroscopy (EIS) was performed under illumination with same light intensity as AM1.5G. The Nyquist plots and fitting curves are illustrated in Fig. 3e, showing two semicircles in the frequency range $100 \mathrm{mHz}$ to 4 MHz. The experimental data were fitted quite well according to the equivalent circuit model shown in the inset of the figure; the fitting parameters are summarized in Table S5 $\uparrow$. For the fitting results, the $R_{\mathrm{S}}$ represents the series resistance of the ITO substrate. The semicircles in the high frequency region are related to $C_{1}$ and $R_{1}$, representing the charge transfer in the perovskite layer; $C_{1}$ might be dominated by the geometric capacitance and may contain components of contact layers responding in a high-frequency domain. ${ }^{36}$ The semicircle represented by $C_{2}$ and $R_{2}$ in the low frequency region reflects the interfacial charge recombination processes. The Nyquist plots show the urea-derived device with a lower charge-transfer resistance $\left(R_{1}\right)$ than that normal device, indicating that the charge transfer inside the perovskite layers were more efficient for the former than latter (the normal cell). The $R_{2}$ of both devices showed similar charge-recombination (RC) resistance, indicating that the CR rates in the perovskite/HTL or perovskite/ ETL interface were similar and this explains both devices have similar open-circuit voltages. These results imply that urea in perovskite could improve the charge transfer of the perovskite layer, thus enhancing the corresponding device performance compared to the reference cell without an additive. Fig. S11 $\dagger$ displayed the PL spectra of the normal and urea derived perovskite films on glass without $\mathrm{NiO}_{x}$. Because of larger crystal size for urea-perovskite, we observed an improvement in the PL intensity. The phenomenon is consistence with TRPL result.

\section{Conclusions}

We have demonstrated a lower temperature perovskites formation process through addition of $1 \%$ urea and $0.5 \%$ thiourea into the precursor of $\mathrm{MAPbI}_{3-x} \mathrm{Cl}_{x}$ or $\mathrm{MAPbI}_{3}$ perovskite. We found that urea can effectively convert the perovskites precursor solution into a better surface, grain size and crystalline perovskite thin film at a relatively low temperature. Through this technique, we improved the PCE of the $\mathrm{MAPbI}_{3-x} \mathrm{Cl}_{x}$ devices from $4.1 \pm 1.0 \%$ to $13.0 \pm 0.4 \%$ with a higher surface coverage from $82.7 \%$ to $97.7 \%$. The addition of urea and thiourea as additives to $\mathrm{MAPbI}_{3}$-based PCSs has similar effects. We found that PCEs can be increased by up to $18.8 \%(18.5 \pm 0.3)$ from the $13.1 \pm 0.3 \%$ at an annealing temperature of $85{ }^{\circ} \mathrm{C}$ for 10 minutes upon adding $1 \%$ urea. PCEs can be increased by up to $16.2 \%(15.9 \pm 0.3 \%)$ from the 7.0 $\pm 0.2 \%$ upon annealing at $65{ }^{\circ} \mathrm{C}$ for 20 minutes after the addition of $1 \%$ urea. The addition of urea and thiourea can promote grain growth and reduce the grain boundary of the thin film in $\mathrm{MAPbI}_{3}$-based devices, allowing the electron and hole to be transferred more effectively. As a result, this additive technique provided modification of defects and traps of perovskites that has improved overall efficiency and reproducibility.

\section{Experimental}

All chemicals were purchased from Aldrich and used as received, unless otherwise specified. MAI was synthesized according to previously reported techniques. ${ }^{37}$ The detailed experimental and fabricated conditions are shown in the ESI. $\dagger$

\section{Conflicts of interest}

There are no conflicts to delcare.

\section{Acknowledgements}

We thank the Ministry of Science and Technology of Taiwan (MOST 106-2113-M-131-001-MY2 and MOST 104-2113-M-009014-MY3) for financial support.

\section{Notes and references}

1 P.-L. Qin, Q. He, C. Chen, X.-L. Zheng, G. Yang, H. Tao, L.-B. Xiong, L. Xiong, G. Li and G.-J. Fang, HighPerformance Rigid and Flexible Perovskite Solar Cells with 
Low-Temperature Solution-Processable Binary Metal Oxide Hole-Transporting Materials, Sol. RRL, 2017, 1(8), 1700058.

2 P. L. Qin, G. Yang, Z. W. Ren, S. H. Cheung, S. K. So, L. Chen, J. Hao, J. Hou and G. Li, Stable and Efficient Organo-Metal Halide Hybrid Perovskite Solar Cells via pi-Conjugated Lewis Base Polymer Induced Trap Passivation and Charge Extraction, Adv. Mater., 2018, 30(12), e1706126.

3 H. L. Zhu, Z. Liang, Z. Huo, W. K. Ng, J. Mao, K. S. Wong, W.-J. Yin and W. C. H. Choy, Low-Bandgap Methylammonium-Rubidium Cation Sn-Rich Perovskites for Efficient Ultraviolet-Visible-Near Infrared Photodetectors, Adv. Funct. Mater., 2018, o(0), 1706068.

4 Z. Zhu, D. Zhao, C.-C. Chueh, X. Shi, Z. Li and A. K. Y. Jen, Highly Efficient and Stable Perovskite Solar Cells Enabled by All-Crosslinked Charge-Transporting Layers, Joule, 2018, 2(1), 168-183.

5 J.-P. Correa-Baena, M. Saliba, T. Buonassisi, M. Grätzel, A. Abate, W. Tress and A. Hagfeldt, Promises and challenges of perovskite solar cells, Science, 2017, 358(6364), 739-744.

6 J. Huang, Y. Yuan, Y. Shao and Y. Yan, Understanding the physical properties of hybrid perovskites for photovoltaic applications, Nat. Rev. Mater., 2017, 2, 17042.

7 T. Li, Y. Pan, Z. Wang, Y. Xia, Y. Chen and W. Huang, Additive engineering for highly efficient organic-inorganic halide perovskite solar cells: recent advances and perspectives, J. Mater. Chem. A, 2017, 5(25), 12602-12652.

8 D. Ouyang, J. Xiao, F. Ye, Z. Huang, H. Zhang, L. Zhu, J. Cheng and W. C. H. Choy, Strategic Synthesis of Ultrasmall $\mathrm{NiCo}_{2} \mathrm{O}_{4} \mathrm{NPs}$ as Hole Transport Layer for Highly Efficient Perovskite Solar Cells, Adv. Energy Mater., 2018, $\mathbf{0}(0), 1702722$.

9 L. Zuo, H. Guo, D. W. deQuilettes, S. Jariwala, N. De Marco, S. Dong, R. DeBlock, D. S. Ginger, B. Dunn, M. Wang and Y. Yang, Polymer-modified halide perovskite films for efficient and stable planar heterojunction solar cells, Sci. Adv., 2017, 3(8), e1700106.

10 J.-W. Lee, S.-H. Bae, Y.-T. Hsieh, N. De Marco, M. Wang, P. Sun and Y. Yang, A Bifunctional Lewis Base Additive for Microscopic Homogeneity in Perovskite Solar Cells, Chem, 2017, 3(2), 290-302.

11 H. L. Hsu, C. C. Chang, C. P. Chen, B. H. Jiang, R. J. Jeng and C. H. Cheng, High-performance and high-durability perovskite photovoltaic devices prepared using ethylammonium iodide as an additive, J. Mater. Chem. A, 2015, 3(17), 9271-9277.

12 N. Li, Z. Zhu, Q. Dong, J. Li, Z. Yang, C. C. Chueh, A. K. Y. Jen and L. Wang, Enhanced Moisture Stability of CesiumContaining Compositional Perovskites by a Feasible Interfacial Engineering, Adv. Mater. Interfaces, 2017, 4(20), 1700598.

13 E. Ercan, J. Y. Chen, P. C. Tsai, J. Y. Lam, S. C. W. Huang, C. C. Chueh and W. C. Chen, A Redox-Based Resistive Switching Memory Device Consisting of Organic-Inorganic Hybrid Perovskite/Polymer Composite Thin Film, Adv. Electron. Mater., 2017, 3(12), 1700344.
14 M. Abdi-Jalebi, Z. Andaji-Garmaroudi, S. Cacovich, C. Stavrakas, B. Philippe, J. M. Richter, M. Alsari, E. P. Booker, E. M. Hutter, A. J. Pearson, S. Lilliu, T. J. Savenije, H. Rensmo, G. Divitini, C. Ducati, R. H. Friend and S. D. Stranks, Maximizing and stabilizing luminescence from halide perovskites with potassium passivation, Nature, 2018, 555, 497.

15 G. Xiu, L. Meng, S. Xiao-Bo, M. Heng, W. Zhao-Kui and L. Liang-Sheng, Controllable Perovskite Crystallization by Water Additive for High-Performance Solar Cells, Adv. Funct. Mater., 2015, 25(42), 6671-6678.

16 J. Lu-Lu, W. Zhao-Kui, L. Meng, Z. Cong-Cong, Y. Qing-Qing, H. Ke-Hao, L. Ding-Ze, F. Peng-Fei and L. Liang-Sheng, Passivated Perovskite Crystallization via $\mathrm{g}-\mathrm{C}_{3} \mathrm{~N}_{4}$ for HighPerformance Solar Cells, Adv. Funct. Mater., 2018, 28(7), 1705875.

17 C.-C. Zhang, M. Li, Z.-K. Wang, Y.-R. Jiang, H.-R. Liu, Y.-G. Yang, X.-Y. Gao and H. Ma, Passivated perovskite crystallization and stability in organic-inorganic halide solar cells by doping a donor polymer, J. Mater. Chem. A, 2017, 5(6), 2572-2579.

18 M. Li, Y.-H. Chao, T. Kang, Z.-K. Wang, Y.-G. Yang, S.-L. Feng, Y. Hu, X.-Y. Gao, L.-S. Liao and C.-S. Hsu, Enhanced crystallization and stability of perovskites by a cross-linkable fullerene for high-performance solar cells, J. Mater. Chem. A, 2016, 4(39), 15088-15094.

19 P. W. Liang, C. Y. Liao, C. C. Chueh, F. Zuo, S. T. Williams, X. K. Xin, J. Lin and A. K. Jen, Additive enhanced crystallization of solution-processed perovskite for highly efficient planar-heterojunction solar cells, Adv. Mater., 2014, 26(22), 3748-3754.

20 C. Zuo and L. Ding, An 80.11\% FF record achieved for perovskite solar cells by using the $\mathrm{NH}_{4} \mathrm{Cl}$ additive, Nanoscale, 2014, 6(17), 9935-9938.

21 C.-M. Hsieh, Y.-L. Yu, C.-P. Chen and S.-C. Chuang, Effects of the additives n-propylammonium or n-butylammonium iodide on the performance of perovskite solar cells, RSC Adv., 2017, 7(88), 55986-55992.

22 Y. Chen, Y. Sun, J. Peng, W. Zhang, X. Su, K. Zheng, T. Pullerits and Z. Liang, Tailoring Organic Cation of 2D Air-Stable Organometal Halide Perovskites for Highly Efficient Planar Solar Cells, Adv. Energy Mater., 2017, 7(18), 1700162.

23 Z. Huang, X. Duan, Y. Zhang, X. Hu, L. Tan and Y. Chen, Pure- or mixed-solvent assisted treatment for crystallization dynamics of planar lead halide perovskite solar cells, Sol. Energy Mater. Sol. Cells, 2016, 155(suppl. C), 166-175.

24 A. R. Pascoe, S. Meyer, W. Huang, W. Li, I. Benesperi, N. W. Duffy, L. Spiccia, U. Bach and Y.-B. Cheng, Enhancing the Optoelectronic Performance of Perovskite Solar Cells via a Textured $\mathrm{CH}_{3} \mathrm{NH}_{3} \mathrm{PbI}_{3}$ Morphology, Adv. Funct. Mater., 2016, 26(8), 1278-1285.

25 Y. Zhang, L. Tan, Q. Fu, L. Chen, T. Ji, X. Hu and Y. Chen, Enhancing the grain size of organic halide perovskites by sulfonate-carbon nanotube incorporation in high 
performance perovskite solar cells, Chem. Commun., 2016, 52(33), 5674-5677.

26 L. Zheng, D. Zhang, Y. Ma, Z. Lu, Z. Chen, S. Wang, L. Xiao and Q. Gong, Morphology control of the perovskite films for efficient solar cells, Dalton Trans., 2015, 44(23), 1058210593.

27 N. K. Noel, A. Abate, S. D. Stranks, E. S. Parrott, V. M. Burlakov, A. Goriely and H. J. Snaith, Enhanced Photoluminescence and Solar Cell Performance via Lewis Base Passivation of Organic-Inorganic Lead Halide Perovskites, ACS Nano, 2014, 8(10), 9815-9821.

28 D. W. deQuilettes, S. Koch, S. Burke, R. K. Paranji, A. J. Shropshire, M. E. Ziffer and D. S. Ginger, Photoluminescence Lifetimes Exceeding $8 \mu \mathrm{s}$ and Quantum Yields Exceeding 30\% in Hybrid Perovskite Thin Films by Ligand Passivation, ACS Energy Lett., 2016, 1(2), 438-444.

29 Y. H. Shao, Z. G. Xiao, C. Bi, Y. B. Yuan and J. S. Huang, Origin and elimination of photocurrent hysteresis by fullerene passivation in $\mathrm{CH}_{3} \mathrm{NH}_{3} \mathrm{PbI}_{3}$ planar heterojunction solar cells, Nat. Commun., 2014, 5, 5784.

30 J. Xu, A. Buin, A. H. Ip, W. Li, O. Voznyy, R. Comin, M. Yuan, S. Jeon, Z. Ning, J. J. McDowell, P. Kanjanaboos, J.-P. Sun, X. Lan, L. N. Quan, D. H. Kim, I. G. Hill, P. Maksymovych and E. H. Sargent, Perovskite-fullerene hybrid materials suppress hysteresis in planar diodes, Nat. Commun., 2015, 6, 7081.

31 D.-Y. Son, J.-W. Lee, Y. J. Choi, I.-H. Jang, S. Lee, P. J. Yoo, H. Shin, N. Ahn, M. Choi, D. Kim and N.-G. Park, Self- formed grain boundary healing layer for highly efficient $\mathrm{CH}_{3} \mathrm{NH}_{3} \mathrm{PbI}_{3}$ perovskite solar cells, Nat. Energy, 2016, 1, 16081.

32 T. Niu, J. Lu, R. Munir, J. Li, D. Barrit, X. Zhang, H. Hu, Z. Yang, A. Amassian, K. Zhao and S. F. Liu, Stable HighPerformance Perovskite Solar Cells via Grain Boundary Passivation, Adv. Mater., 2018, o(0), 1706576.

33 L. Zhu, Y. Xu, P. Zhang, J. Shi, Y. Zhao, H. Zhang, J. Wu, Y. Luo, D. Li and Q. Meng, Investigation on the role of Lewis bases in the ripening process of perovskite films for highly efficient perovskite solar cells, J. Mater. Chem. A, 2017, 5(39), 20874-20881.

34 H.-L. Hsu, C.-P. Chen, J.-Y. Chang, Y.-Y. Yu and Y.-K. Shen, Two-step thermal annealing improves the morphology of spin-coated films for highly efficient perovskite hybrid photovoltaics, Nanoscale, 2014, 6(17), 10281.

35 J. Joseph and E. D. Jemmis, Red-, Blue-, or No-Shift in Hydrogen Bonds: A Unified Explanation, J. Am. Chem. Soc., 2007, 129(15), 4620-4632.

36 F. Behrouznejad, C.-M. Tsai, S. Narra, E. W. G. Diau and N. Taghavinia, Interfacial Investigation on Printable Carbon-Based Mesoscopic Perovskite Solar Cells with $\mathrm{NiO}_{\mathrm{x}} /$ C Back Electrode, ACS Appl. Mater. Interfaces, 2017, 9(30), 25204-25215.

37 H.-L. Hsu, C.-C. Chang, C.-P. Chen, B.-H. Jiang, R.-J. Jeng and C.-H. Cheng, High-performance and high-durability perovskite photovoltaic devices prepared using ethylammonium iodide as an additive, J. Mater. Chem. A, 2015, 3(17), 9271-9277. 